\title{
Chronotype and Health Outcomes
}

\author{
Timo Partonen ${ }^{1}$
}

Published online: 26 September 2015

(C) Springer International Publishing AG 2015

\begin{abstract}
The behavioral trait of preference to schedule the daily activities for morning or evening hours forms a continuum, with the anchorage ends of "early birds" and "night owls," and is called chronotype. Genetic effects contribute to the chronotype by about half and the other half is accounted for non-shared environmental effects. However, no "chronotype gene" has been identified yet. There is a growing body of literature on health hazards that has been attributed to the chronotype itself, being independent of a number of factors. So far, without any exception, of those health hazards that do differ between the chronotypes, all have been more common among the "night owls" than among the "early birds," such as mood disorders, anxiety disorders, substance use disorders, personality disorders, insomnia, sleep apnea, arterial hypertension, bronchial asthma, type 2 diabetes, and infertility. Alarmingly, current data suggest that "night owls" tend to die younger than "early birds".
\end{abstract}

Keywords Activity · Bipolar · Cardiovascular · Chronotype · Circadian · Depressive $\cdot$ Diurnal $\cdot$ Eveningness $\cdot$ Metabolic $\cdot$ Mood $\cdot$ Morningness $\cdot$ Population $\cdot$ Pulmonary $\cdot$

Reproduction $\cdot$ Sleep

This article is part of the Topical Collection on Sleep Epidemiology

Timo Partonen

timo.partonen@thl.fi

1 Department of Health, Mental Health Unit, National Institute for Health and Welfare, P.O. Box 30, FI-00271 Helsinki, Finland

\section{Introduction}

Oscillations of endogenous biological processes that follow the approximate 24-h, that is circadian, rhythm exist in diverse organisms and arise as an adaptive mechanism to the Earth's rotation producing the foreseeable transitions of night and day. These oscillations are generated and maintained by endogenous circadian clocks.

In the beginning of life, 3.5 to 3.9 billion years ago, the length of day was about $14 \mathrm{~h}$ and ultraviolet radiation was not filtered by the Earth's atmosphere. Thus, circadian clocks met the night-day transitions with the approximate period of $14 \mathrm{~h}$ and were readily involved in protection from ultraviolet radiation. Thereafter, the period has lengthened, along with which circadian clocks have evolved a slowing-down mechanism [1, 2] and adopted periods of longer than $14 \mathrm{~h}$ up to the current one of about $24 \mathrm{~h}$ as the reference. Circadian clocks are endogenous pacemakers that evolve their properties, when subjected to selection, but have remained conservative during evolution [3].

The individual's sleep-wake (rest-activity) cycle is a product of the homeostatic sleep process and the circadian process that interact with each other [4] but appears to be dictated mostly by the latter [5]. The endogenous circadian rhythms are normally aligned with the individual's sleep-wake cycle. Therefore, the behavioral trait of preference to schedule the daily activities for morning or evening hours can be estimated from the timing of sleep phase (bedtime to wake-up time), although the estimates need to be corrected for potential sleep debt. These preferences form a continuum which has the anchorage ends of morning-oriented preference ("early birds") and evening-oriented preference ("night owls") [6].

The endogenous circadian period correlates with the subjective report of this behavioral trait, with the circadian phase, and with the wake-up time [7]. The estimates of the 
endogenous circadian period from 52 women and 105 men, healthy and aged 18-74 years, revealed that the period of the circadian rhythms of melatonin concentration and core body temperature was close to $24 \mathrm{~h}$ on average, but shorter in women $(24 \mathrm{~h} 5 \mathrm{~min} \pm 12 \mathrm{~min})$ than that in men $(24 \mathrm{~h} 11 \mathrm{~min} \pm$ $12 \mathrm{~min}$ ) [8]. Of note, however, there was no influence of age on the endogenous circadian period [8].

On the basis of twin studies, it is estimated that the genetic effects contribute to the chronotype by about half and the other half is accounted by environmental factors $[9,10,11 \cdot, 12 \cdot, 13]$. It is suggested that for a given chronotype, the genetic effects may not operate in an additive manner [9], but the underlying liability to chronotype was $38 \%$ on average for the genetic factors due to dominance [10]. Further, there are no gender differences for the magnitude of the genetic and environmental effects $[9,10]$, nor is the magnitude of these effects influenced by age [10].

The continuum of chronotype diversity is largely mediated by genes, and the schedule of gene expression is fundamentally different, not just merely advanced or delayed, between the "early birds" and "night owls" [14]. In such epigenetic landscape, a single genotype can thereby lead to different phenotypes. Moreover, different genes for the chronotype are expressed in different generations [9]. These phenomena might explain the currently equivocal data on genetic associations with chronotype.

The endogenous circadian clock of "early birds" tracks an earlier hour, as compared with that of "night owls," with respect to both the social clock time and the individual wake-up time. Most of the individuals have a preference as intermediate with respect to these two extremes. Under such conditions where it is allowed to consider only the individual's "feeling best" rhythm for planning the day, such as on free days in real life or in constant routine at a sleep research laboratory, the chronotype can be assessed accurately. There are a number of instruments for assessment of the chronotype (see Table 1).

The assessment of chronotype has gained attention as working in shifts has become more and more usual, and there is a growing body of literature on health hazards that are related to shift work, especially to night shift work [15].
However, the assessment of chronotype may be highly relevant not only for shift workers but also for others as well. During the past 10 years, health hazards have been attributed to the chronotype itself, being independent of working in shifts, and a summary of potential associated health hazards is presented in Table 2. Therefore, we believe that additional research on the health hazards of "night owls" is needed [16].

\section{Health-Related Behavioral Outcomes}

Earlier small-scale studies have demonstrated that "night owls" drink more alcohol [17], smoke more tobacco [18], keep more often irregular or unhealthy diets $[19,20]$, are less often engaged in physical activity [21], and sleep less or have poorer sleep quality [22-26] than others. Recently, these findings have been verified in a series of studies using a national health examination study dataset on a sample of 6858 adults, aged 25 to 74 years, derived from the general population of Finland [27-31].

Considering all these findings, it is thus not unexpected to find that substance abuse or dependence are more frequent among "night owls" [32], although at least in the presence of bipolar disorder it seems that "early birds" are more prone to substance use disorders [33]. Furthermore, overweight $[34,35 \bullet]$ and sleep apnea [36] are more frequent among "night owls".

All the aforementioned results on "night owls," when compared to early birds," have a tendency to have less resilience to adversity and less optimism for life [37], worse academic achievement both as school pupils and as university students [38], and having difficulties in their adaptation to an work environment that switches frequently or irregularly between shifts [39, 40॰]. But, it may not necessarily need to be this way, as the circadian disruption can be alleviated by adjusted shift schedules [41]. Further, among the "night owls," there appears to be a subgroup of individuals who have equal cardiovascular risks, sleep well and present similar levels of academic achievement to those of the majority of "early birds" [30, 42].

Table 1 Assessment of chronotype

\begin{tabular}{lll}
\hline Measure & Instrument & Comment \\
\hline $\begin{array}{l}\text { Self-report on preference } \\
\text { Rest-activity cycle (actogram) }\end{array}$ & $\begin{array}{l}\text { Morningness/eveningness questionnaire [6] } \\
\text { Accelerometer (actigraphy) }\end{array}$ & $\begin{array}{l}\text { The golden standard scale for self-rating of chronotype } \\
\text { Continuous recording of rest-activity counts to reveal the } \\
\text { sleep-wake schedule and to estimate the circadian rhythm } \\
\text { Continuous recording of body temperature to analyze the } \\
\text { circadian rhythm parameters. Record of rectal temperature } \\
\text { is the golden standard method }\end{array}$ \\
\hline
\end{tabular}


Table 2 Health-related hazards among "night owls"

\begin{tabular}{lll}
\hline Physiology & Condition & Disease \\
\hline Brain & Alcohol misuse & Alcohol abuse \\
& Smoking & Nicotine dependence \\
& Irregular or unhealthy diet & \\
& Low physical activity & \\
& Irregular or deprived sleep & \\
& Sleeping difficulties & \\
& Overweight & Insomnia \\
& Sleep disturbances & \\
& Depressive symptoms & Sleep apnea \\
& Depression, hypomania, or mania & Depressive disorder \\
& Anxiety & Bipolar disorder \\
Heart and blood vessels & & Anxiety disorder \\
Lungs and respiratory tract & Wheezy breathing & Personality disorder \\
Endocrine organs & Allergic respiratory symptoms & Arterial hypertension \\
& Reduced insulin sensitivity, reduced & Bronchial asthma \\
& glucose tolerance, poorer glycemic & Hay fever \\
& Difficulties in getting pregnant & Type 2 diabetes \\
& & \\
& & Infertility \\
\hline
\end{tabular}

\section{Mental Health Outcomes}

The assessment of chronotype in a sample of healthy persons, aged 18 to 99 years, demonstrated that "night owls" had more severe depressive symptoms, especially those of sadness, inner tension, sleep reduction and pessimism, than others [43]. Among adolescents (aged 12 to 18 years), the chronotype of "night owls" appeared to be a risk factor for depressive symptoms and insomnia, but not for anxiety [44]. This finding is in agreement with that among adults aged 20 to 59 years, "night owls" had increased odds for having depressive states which appear to be independent of sleep parameters [45]. The original report on the association of the "night owls" with depressive disorder compared 39 patients with 39 matched controls [46]. Thereafter, these findings have been replicated and extended by using a national population-based data on adults aged 25 to 74 years $[47,48]$.

The increased odds for bipolar disorder, either type 1 or type 2, was initially reported from 190 patients and 128 community-driven controls [49]. Thereafter, during the follow-up of 4 years on average, patients with bipolar disorder remained as "night owls" more frequently, regardless of their current mood state, as compared with healthy controls $[50 \bullet \cdot$.

Beyond mood disorders, the chronotype of "night owls" appears to be more common among individuals with anxiety and substance use disorders [51]. In addition, studies have shown that "night owls" tend to have a past diagnosis of more than just one mental disorder or, in other words, a higher prevalence of co-morbid conditions [51,52].
On the admission day to hospital treatment, patients with personality disorder, substance use disorder or anxiety disorder were more often "night owls," whereas those with psychotic disorder or depressive disorder were more often "early birds" [53]. Even though these findings may seem contradictory to the earlier reports, it has been proposed that "earlybird"-like circadian rhythms might play as a relief factor after the onset of major depressive episode [54]. Currently, it is not known whether this action of relief, if it were to be true, is linked to an attempt to reset the circadian rhythms. The reset hypothesis of mood disorders, claiming therapeutic effects from resetting the desynchronized circadian rhythms, has been put forward and gained experimental support [55-57]. In agreement with this hypothesis are the finding that "night owls" had the increased odds for non-remission of a depressive episode, independent of insomnia [58.] and that, in patients with insomnia, the closer the chronotype was to that of the "night owls," the less alleviation of depressive symptoms there was after group cognitive behavioral therapy [59].

\section{General Medical Health Outcomes}

The influence of the chronotype is not limited to mental health outcomes but is associated with general health outcomes, thus potentially having a high impact on public health. In a national health examination study representative of adults aged 25 to 74 years in Finland, it was found that "night owls" had the increased odds for arterial hypertension, even after controlling for sleep duration and insufficient sleep [60]. 
Animal models have suggested that individuals with a longer circadian period due to a single deficient circadian clock protein are predisposed to weight gain and disturbances in glucose metabolism, reduced insulin sensitivity, and reduced glucose tolerance, leading to a condition similar to the metabolic syndrome [61]. Non-invasively, housing mice in the 20-h light-dark cycles disrupts their endogenous circadian period and results on a similar condition [62]. Furthermore, human experiments have demonstrated similar effects after sleep deprivation in healthy volunteers [63] and in patients with type 1 diabetes [64], as well as in healthy volunteers after disruption of the circadian clock functions [65].

Considering the aforementioned findings, it is not surprising to see that among patients with type 2 diabetes, independently of sleep disturbances, those whose chronotype was closer to the "night owls" had poorer glycemic control as assessed with the concentrations of glycohemoglobin [66-68]. These findings were extended by studies where "night owls" had the increased odds for type 2 diabetes in a sample of adults aged 25 to 74 years [60] and in another sample of adults aged 47 to 59 years [69].

Beyond cardiovascular and metabolic risks, "night owls" have higher prevalence of wheezy breathing without respiratory infection, a diagnosed or treated bronchial asthma, awoken in shortness of breath, awoken in heavy to breath, wheezy breathing with dyspnea, wheezy breathing as such, and medication for asthma more often than "early birds" [70]. Further, among women aged 25 to 54 years and still menstruating, the closer the chronotype was to the "night owls," the longer the menstrual bleeding was and the higher the prevalence of infertility was [71•].

\section{Chronotypes over the Course of Life}

First, in early childhood, circadian preferences that are close to the "early birds" seems to best characterize the preference in healthy children aged 30 to 36 months, whereas none were definitely "night owls" [72].

During the puberty, among adolescents aged 10 to 16 years, the buildup of sleep pressure that increases sleepiness over the course of day was slower among those whose puberty was more advanced than that of the others [73]. Further, among adolescents aged 9 to 19 years, the dissipation of sleep pressure did not change across adolescent development nor correlated with the circadian phase [74]. However, after puberty, among persons aged 19 to 34 years with intermediate circadian phases, both the baseline level and decay rate of slow-wave activity during the night-time sleep were higher in "early birds" than that in "night owls," but the extreme chronotypes did not differ from each other [75]. The latter one of these findings [75] suggests that chronotype may originate from some fundamental differences in the dissipation of sleep pressure, whereas the first one [74] appears to contradict this notion. Thus, the sleep and circadian processes influence the sleep-wake schedule preference independently, but the roots of chronotype may lie in the circadian process rather than in the sleep process. This assumption agrees with the proposed three-oscillator model [5].

Finally, in late adulthood among seniors aged 65 to 94 years, circadian preferences that are close to the "early birds" are again more common than other chronotypes [76]. Such findings have suggested that the chronotype changes with aging toward a more morning-type preference. However, these data were based on cross-sectional samples, and as the longitudinal data on the chronotype of the same persons as assessed with the same methods were missing, until recently there was no answer to the question whether the chronotype changes with aging.

To answer this aforementioned question, a longitudinal dataset on individuals aged 57 to 97 years was analyzed and revealed that there was a shift from "night owls" to another chronotype with aging from the years of 1985 to 2008 [77••]. The closer to the "early birds" the chronotype was, the more persistent it remained with aging [77••]. Alarmingly, the relative risk of all-cause mortality was on average 1.3 -fold (95\% confidence interval of 1.0-1.6) higher for "night owls" as compared with "early birds," these premature deaths starting to emerge after the age of 55 years [77••]. It is of note here that these data concerned only men and that such data on women are still missing. However, this finding supports the view that with aging, the decreased proportion of "night owls" is partly due to premature mortality in this group.

Recently, a view on the distribution of chronotypes among older age groups proposed that "night owls" tend to die younger than "early birds" [78]. The finding of the increased allcause mortality among the "night owls" is new and supports the view, but currently there is no clear explanation to it. However, it holds that "night owls" do have greater deviations of their circadian period from the 24-h period than others [7]. It is not known how this may link to their greater morbidity or mortality or whether their greater morbidity or mortality is due to a sustained drive for delays and subsequent circadian disruption. This view might not be far-fetched though, because currently all the health hazards that associate with chronotype are more frequent among "night owls," and this is likely to contribute to subsequent morbidity and thereby potentially to all-cause mortality.

\section{Future Directions}

There are still many research questions on the chronotype that await elucidation. One of these 
"scientific coconuts" that await breakthrough experiments for explanation is the change in chronotype with aging. During the puberty, there seems to be a subgroup of adolescents who gravitate toward the preference of the "night owls" and who remain as such. It will be not only of importance to health promotion but also of clinical relevance to find out the key mechanisms that favor this gravitation of chronotype, identify persons who remain at clinically meaningful risk and provide them a protective intervention early enough.

Another goal is to collect more data from big-scale population-based studies to have valid estimates of the prevalence rates of chronotypes and their associations with outcomes of health status after controlling for potential confounding or masking. Ideally, such studies need to provide data that are representative of the whole population, or persons aged 0 to 120 years. These actions will initiate a series of cohort studies and eventually help in solving the problem of chronotype gravitation. In addition, prospective design for these studies will clarify the causal relationships between the chronotype and the attributed conditions. This call is out for all research groups on the topic.

As "night owls" have equal sleep durations and dissipation rates of sleep pressure to others, it remains to be seen instead whether "night owls" have a stronger slowing-down mechanism in their circadian clocks than others. Such property may lead to a longer circadian period and a slower buildup of sleep pressure during wakefulness, which tends to characterize the "night owls".

\section{Conclusions}

So far, without any exception, of those health hazards that do differ between the chronotypes, all have been more common among the "night owls" as compared with the "early birds." Therefore, the routine assessment of chronotype as part of health status examinations in health-care settings on every level and early enough seems not only relevant but also urgent.

\section{Compliance with Ethics Guidelines}

Conflict of Interest Timo Partonen has received royalties and speaker fees from Dila, Duodecim Medical Publications Ltd, Helen Ltd, Helsinki Fair Ltd, MCD-Team Oy, MERCURIA, Oxford University Press, Oy H. Lundbeck Ab, Servier Finland Oy, and YTHS outside of the submitted work.

Human and Animal Rights and Informed Consent This article does not contain any studies with human or animal subjects performed by any of the authors.

\section{References}

Papers of particular interest, published recently, have been highlighted as:

- Of importance

• Of major importance

1. Chang YG, Cohen SE, Phong C, Myers WK, Kim YI, Tseng R, et al. A protein fold switch joins the circadian oscillator to clock output in cyanobacteria. Science. 2015;349:324-8.

2. Abe J, Hiyama TB, Mukaiyama A, Son S, Mori T, Saito S, et al. Atomic-scale origins of slowness in the cyanobacterial circadian clock. Science. 2015;349:312-6.

3. Rosbash M. The implications of multiple circadian clock origins. PLoS Biol. 2009;7:e62.

4. Borbély AA. A two process model of sleep regulation. Hum Neurobiol. 1982;1:195-204.

5. Kawato M, Fujita K, Suzuki R, Winfree AT. A three-oscillator model of the human circadian system controlling the core temperature rhythm and the sleep-wake cycle. J Theor Biol. 1982;98:369-92.

6. Horne JA, Östberg O. A self-assessment questionnaire to determine morningness-eveningness in human circadian rhythms. Int $\mathrm{J}$ Chronobiol. 1976;4:97-110.

7. Duffy JF, Rimmer DW, Czeisler CA. Association of intrinsic circadian period with morningness-eveningness, usual wake time, and circadian phase. Behav Neurosci. 2001;115:895-9.

8. Duffy JF, Cain SW, Chang AM, Phillips AJ, Münch MY, Gronfier $\mathrm{C}$, et al. Sex difference in the near-24-hour intrinsic period of the human circadian timing system. Proc Natl Acad Sci U S A. 2011;108 Suppl 3:15602-8.

9. Vink JM, Groot AS, Kerkhof GA, Boomsma DI. Genetic analysis of morningness and eveningness. Chronobiol Int. 2001;18:809-22.

10. Koskenvuo M, Hublin C, Partinen M, Heikkilä K, Kaprio J. Heritability of diurnal type: a nationwide study of 8753 adult twin pairs. J Sleep Res. 2007;16:156-62.

11. Toomey R, Panizzon MS, Kremen WS, Franz CE, Lyons MJ. A twin-study of genetic contributions to morningness-eveningness and depression. Chronobiol Int. 2015;32:303-9. This twin-study showed that chronotype and depression share a substantial amount of their underlying genetic variance and suggested an overlap in etiology.

12. Barclay NL, Eley TC, Parsons MJ, Willis TA, Gregory AM. Monozygotic twin differences in non-shared environmental factors associated with chronotype. J Biol Rhythm. 2013;28:51-61. This twin-study confirmed that that shared environment accounts for little, if any, variance in chronotype.

13. Watson NF, Buchwald D, Harden KP. A twin study of genetic influences on diurnal preference and risk for alcohol use outcomes. J Clin Sleep Med. 2013;9:1333-9.

14. Pegoraro M, Picot E, Hansen CN, Kyriacou CP, Rosato E, Tauber E. Gene expression associated with early and late chronotypes in Drosophila melanogaster. Front Neurol. 2015;6:100.

15. Stevens RG, Hansen J, Costa G, Haus E, Kauppinen T, Aronson $\mathrm{KJ}$, et al. Considerations of circadian impact for defining 'shift work' in cancer studies: IARC Working Group Report. Occup Environ Med. 2011;68:154-62.

16. Partonen T. Pay attention to evening owls. Ann Med. 2013;45:395-6.

17. Adan A. Chronotype and personality factors in the daily consumption of alcohol and psychostimulants. Addiction. 1994;89:455-62.

18. Negriff S, Dorn LD, Pabst SR, Susman EJ. Morningness/ eveningness, pubertal timing, and substance use in adolescent girls. Psychiatry Res. 2011;185:408-13. 
19. Nakade M, Takeuchi H, Kurotani M, Harada T. Effects of meal habits and alcohol/cigarette consumption on morningnesseveningness preference and sleep habits by Japanese female students aged 18-29. J Physiol Anthropol. 2009;28:83-90.

20. Haraszti RÁ, Purebl G, Salavecz G, Poole L, Dockray S, Steptoe A. Morningness-eveningness interferes with perceived health, physical activity, diet and stress levels in working women: a crosssectional study. Chronobiol Int. 2014;31:829-37.

21. Urbán R, Magyaródi T, Rigó A. Morningness-eveningness, chronotypes and health-impairing behaviors in adolescents. Chronobiol Int. 2011;28:238-47.

22. Carrier J, Monk TH, Buysse DJ, Kupfer DJ. Sleep and morningness-eveningness in the 'middle' years of life (20-59 y). J Sleep Res. 1997;6:230-7.

23. Park YM, Matsumoto K, Seo YJ, Shinkoda H. Sleep and chronotype for children in Japan. Percept Mot Skills. 1999;88(3 Pt 2):1315-29.

24. Taillard J, Philip P, Bioulac B. Morningness/eveningness and the need for sleep. J Sleep Res. 1999;8:291-5.

25. Giannotti F, Cortesi F, Sebastiani T, Ottaviano S. Circadian preference, sleep and daytime behaviour in adolescence. J Sleep Res. 2002;11:191-9.

26. Gau SS, Shang CY, Merikangas KR, Chiu YN, Soong WT, Cheng AT. Association between morningness-eveningness and behavioral/ emotional problems among adolescents. J Biol Rhythm. 2007;22: 268-74.

27. Merikanto I, Lahti T, Seitsalo S, Kronholm E, Laatikainen T, Peltonen $\mathrm{M}$, et al. Behavioral trait of morningness-eveningness in association with articular and spinal diseases in a population. PLoS One. 2014;9:e114635.

28. Broms U, Pennanen M, Patja K, Ollila H, Korhonen T, Haukkala A, et al. Diurnal evening type is associated with current smoking, nicotine dependence and nicotine intake in the population based National FINRISK 2007 Study. J Addict Res Ther. 2012;25 Suppl 2:002.

29. Kanerva N, Kronholm E, Partonen T, Ovaskainen M-L, Kaartinen $\mathrm{NE}$, Konttinen $\mathrm{H}$, et al. Tendency toward eveningness is associated with unhealthy dietary habits. Chronobiol Int. 2012;29:920-7.

30. Wennman H, Kronholm E, Partonen T, Peltonen M, Vasankari T, Borodulin K. Evening typology and morning tiredness associate with low leisure time physical activity and high sitting. Chronobiol Int. 2015. doi:10.3109/07420528.2015.1063061.

31. Merikanto I, Kronholm E, Peltonen M, Laatikainen T, Lahti T, Partonen T. Relation of chronotype to sleep complaints in the general Finnish population. Chronobiol Int. 2012;29:311-7.

32. Hasler BP, Sitnick SL, Shaw DS, Forbes EE. An altered neural response to reward may contribute to alcohol problems among late adolescents with an evening chronotype. Psychiatry Res. 2013;214: 357-64.

33. Hätönen T, Forsblom S, Kieseppä T, Lönnqvist J, Partonen T. Circadian phenotype in patients with the co-morbid alcohol use and bipolar disorders. Alcohol Alcohol. 2008;43:564-8.

34. Baron KG, Reid KJ, Kern AS, Zee PC. Role of sleep timing in caloric intake and BMI. Obesity (Silver Spring). 2011;19:1374-81.

35. Arora T, Taheri S. Associations among late chronotype, body mass index and dietary behaviors in young adolescents. Int $\mathrm{J}$ Obes. 2015;39:39-44. This study on adolescents showed that "night owls" had a greater body-mass index and less healthy dietary habits than "early birds".

36. Lucassen EA, Zhao X, Rother KI, Mattingly MS, Courville AB, de Jonge L, et al. Evening chronotype is associated with changes in eating behavior, more sleep apnea, and increased stress hormones in short sleeping obese individuals. PLoS One. 2013;8:e56519.

37. Antúnez JM, Navarro JF, Adan A. Circadian typology is related to resilience and optimism in healthy adults. Chronobiol Int. 2015;32: 524-30.
38. Tonetti L, Natale V, Randler C. Association between circadian preference and academic achievement: a systematic review and metaanalysis. Chronobiol Int. 2015;32:792-801.

39. Gamble KL, Motsinger-Reif AA, Hida A, Borsetti HM, Servick SV, Ciarleglio CM, et al. Shift work in nurses: contribution of phenotypes and genotypes to adaptation. PLoS One. 2011;6:e18395.

40. Martin JS, Laberge L, Sasseville A, Bérubé M, Alain S, Houle J, et al. Day and night shift schedules are associated with lower sleep quality in Evening-types. Chronobiol Int. 2015;32:627-36. This field study on shift workers challenged the assumption that "night owls" adapt better to night shifts.

41. Vetter C, Fischer D, Matera JL, Roenneberg T. Aligning work and circadian time in shift workers improves sleep and reduces circadian disruption. Curr Biol. 2015;25:907-11.

42. Tavernier R, Willoughby T. Are all evening-types doomed? Latent class analyses of perceived morningness-eveningness, sleep and psychosocial functioning among emerging adults. Chronobiol Int. 2014;31:232-42.

43. Hidalgo MP, Caumo W, Posser M, Coccaro SB, Camozzato AL, Chaves ML. Relationship between depressive mood and chronotype in healthy subjects. Psychiatry Clin Neurosci. 2009;63:283-90.

44. Alvaro PK, Roberts RM, Harris JK. The independent relationships between insomnia, depression, subtypes of anxiety, and chronotype during adolescence. Sleep Med. 2014;15(8):934-41.

45. Kitamura S, Hida A, Watanabe M, Enomoto M, Aritake-Okada S, Moriguchi $Y$, et al. Evening preference is related to the incidence of depressive states independent of sleep-wake conditions. Chronobiol Int. 2010;27:1797-812.

46. Drennan MD, Klauber MR, Kripke DF, Goyette LM. The effects of depression and age on the Horne-Ostberg morningnesseveningness score. J Affect Disord. 1991;23:93-8.

47. Merikanto I, Lahti T, Kronholm E, Peltonen M, Laatikainen T, Vartiainen E, et al. Evening types are prone to depression. Chronobiol Int. 2013;30:719-25.

48. Konttinen H, Kronholm E, Partonen T, Kanerva N, Männistö S, Haukkala A. Morningness-eveningness, depressive symptoms, and emotional eating: a population-based study. Chronobiol Int. 2014;31:554-63.

49. Wood J, Birmaher B, Axelson D, Ehmann M, Kalas C, Monk K, et al. Replicable differences in preferred circadian phase between bipolar disorder patients and control individuals. Psychiatry Res. 2009;166:201-9.

50.• Seleem MA, Merranko JA, Goldstein TR, Goldstein BI, Axelson DA, Brent DA, et al. The longitudinal course of sleep timing and circadian preferences in adults with bipolar disorder. Bipolar Disord. 2015;17:392-402. This longitudinal study showed that patients with bipolar disorder are tended to be "night owls" regardless of their current mood state.

51. Reid KJ, Jaksa AA, Eisengart JB, Baron KG, Lu B, Kane P, et al. Systematic evaluation of Axis-I DSM diagnoses in delayed sleep phase disorder and evening-type circadian preference. Sleep Med. 2012;13:1171-7.

52. Merikanto I, Suvisaari J, Lahti T, Partonen T. Eveningness relates to burnout and seasonal sleep and mood problems among young adults. Nord J Psychiatry. 2015. doi:10.3109/08039488.2015. 1053519.

53. Lemoine P, Zawieja P, Ohayon MM. Associations between morningness/eveningness and psychopathology: an epidemiological survey in three in-patient psychiatric clinics. J Psychiatr Res. 2013;47:1095-8.

54. Selvi Y, Aydin A, Boysan M, Atli A, Agargun MY, Besiroglu L. Associations between chronotype, sleep quality, suicidality, and depressive symptoms in patients with major depression and healthy controls. Chronobiol Int. 2010;27:1813-28. 
55. Bunney BG, Bunney WE. Rapid-acting antidepressant strategies: mechanisms of action. Int $\mathrm{J}$ Neuropsychopharmacol. 2012;15:695-713.

56. Bunney BG, Bunney WE. Mechanisms of rapid antidepressant effects of sleep deprivation therapy: clock genes and circadian rhythms. Biol Psychiatry. 2013;73:1164-71.

57. Bunney BG, Li JZ, Walsh DM, Stein R, Vawter MP, Cartagena P, et al. Circadian dysregulation of clock genes: clues to rapid treatments in major depressive disorder. Mol Psychiatry. 2015;20:48-55.

58. Chan JW, Lam SP, Li SX, Yu MW, Chan NY, Zhang J, et al. Eveningness and insomnia: independent risk factors of nonremission in major depressive disorder. Sleep. 2014;37:911-7. This cohort study showed that, among patients with major depressive disorder, "night owls" had the increased odds for nonremission.

59. Bei B, Ong JC, Rajaratnam SM, Manber R. Chronotype and improved sleep efficiency independently predict depressive symptom reduction after group cognitive behavioral therapy for insomnia. J Clin Sleep Med. 2015;11:1021-7.

60. Merikanto I, Lahti T, Puolijoki H, Vanhala M, Peltonen M, Laatikainen T, et al. Associations of chronotype and sleep with cardiovascular diseases and type 2 diabetes. Chronobiol Int. 2013;30:470-7.

61. Turek FW, Joshu C, Kohsaka A, Lin E, Ivanova G, McDearmon E, et al. Obesity and metabolic syndrome in circadian clock mutant mice. Science. 2005;308:1043-5.

62. Karatsoreos IN, Bhagat S, Bloss EB, Morrison JH, McEwen BS. Disruption of circadian clocks has ramifications for metabolism, brain, and behavior. Proc Natl Acad Sci U S A. 2011;108:1657-62.

63. Spiegel K, Leproult R, Van Cauter E. Impact of sleep debt on metabolic and endocrine function. Lancet. 1999;354:1435-9.

64. Donga E, van Dijk M, van Dijk JG, Biermasz NR, Lammers GJ, van Kralingen $\mathrm{K}$, et al. Partial sleep restriction decreases insulin sensitivity in type 1 diabetes. Diabetes Care. 2010;33:1573-7.

65. Morris CJ, Yang JN, Garcia JI, Myers S, Bozzi I, Wang W, et al. Endogenous circadian system and circadian misalignment impact glucose tolerance via separate mechanisms in humans. Proc Natl Acad Sci U S A. 2015;112:E2225-34.

66. Reutrakul S, Hood MM, Crowley SJ, Morgan MK, Teodori M, Knutson KL, et al. Chronotype is independently associated with glycemic control in type 2 diabetes. Diabetes Care. 2013;36: 2523-9.
67. Osonoi Y, Mita T, Osonoi T, Saito M, Tamasawa A, Nakayama S, et al. Morningness-eveningness questionnaire score and metabolic parameters in patients with type 2 diabetes mellitus. Chronobiol Int. 2014;31:1017-23.

68. Iwasaki M, Hirose T, Mita T, Sato F, Ito C, Yamamoto R, et al. Morningness-eveningness questionnaire score correlates with glycated hemoglobin in middle-aged male workers with type 2 diabetes mellitus. J Diabetes Investig. 2013;4:376-81.

69. Yu JH, Yun CH, Ahn JH, Suh S, Cho HJ, Lee SK, et al. Evening chronotype is associated with metabolic disorders and body composition in middle-aged adults. J Clin Endocrinol Metab. 2015;100: 1494-502.

70. Merikanto I, Englund A, Kronholm E, Laatikainen T, Peltonen T, Vartiainen E, et al. Evening chronotypes have the increased odds for bronchial asthma and nocturnal asthma. Chronobiol Int. 2014;31: 95-101.

71. Toffol E, Merikanto I, Lahti T, Luoto R, Heikinheimo O, Partonen T. Evidence for a relationship between chronotype and reproductive function in women. Chronobiol Int. 2013;30:756-65. This population-based health examination study showed that "night owls" have had difficulties in getting pregnant more often than others.

72. Simpkin CT, Jenni OG, Carskadon MA, Wright Jr KP, Akacem LD, Garlo KG, et al. Chronotype is associated with the timing of the circadian clock and sleep in toddlers. J Sleep Res. 2014;23: 397-405.

73. Jenni OG, Achermann P, Carskadon MA. Homeostatic sleep regulation in adolescents. Sleep. 2005;28:1446-54.

74. Tarokh L, Carskadon MA, Achermann P. Dissipation of sleep pressure is stable across adolescence. Neuroscience. 2012;216:167-77.

75. Mongrain V, Carrier J, Dumont M. Circadian and homeostatic sleep regulation in morningness-eveningness. J Sleep Res. 2006;15:162-6.

76. Monk TH, Buysse DJ. Chronotype, bed timing and total sleep time in seniors. Chronobiol Int. 2014;31:655-9.

77.• Broms U, Pitkäniemi J, Bäckmand H, Heikkilä K, Koskenvuo M, Peltonen M, et al. Long-term consistency of diurnal-type preferences among men. Chronobiol Int. 2014;31:182-8. This longitudinal study showed that "night owls" tend to die younger than "early birds".

78. Partonen T. Hypothesis: cryptochromes and brown fat are essential for adaptation and affect mood and mood-related behaviors. Front Neurol. 2012;3:157. 